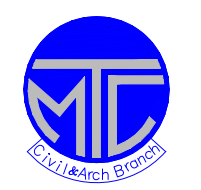

\title{
ICCAE
}

Military Technical College

Kobry Elkobbah,

Cairo, Egypt

\author{
7 th International Conference \\ On Civil \& Architecture \\ Engineering
}

\section{DEVELOPMENT OF A LONG DISTANCE TRIP GENERATION MODEL: CASE STUDY}

\author{
A. El-Desouky ${ }^{*}$, K. Kandil ${ }^{* *}$, A. Mostafa ${ }^{* * *}$, and S. Easa ${ }^{* * * *}$
}

\begin{abstract}
In traditional four-step travel demand forecasting, trip generation modeling is the first analytic process undertaken to determine travel demand in terms of trip rates or total trips. As trip generation is the first stage of the modeling process, errors here are carried through the entire process and may invalidate work on subsequent stages. The American travel survey (ATS), conducted by the bureau of transportation statistics (BTS) in 1995 represents a database of long distance passenger travel information collected by the federal government. It served as the primary data source for this investigation. The main objective of this paper is to develop a simple long distance trip generation model for metropolitan areas. Effect of metropolitan income on the total number of generated trips is also incorporated in this study. The presented model can be calibrated and used outside the states.
\end{abstract}

\section{INTRODUCTION}

Trip generation is the decision to travel for a specific purpose. It aims at predicting the total number of trips generated by origin. Many factors affect the process of trip generation as; income, car ownership, household structure, family size, value of land, residential density, and accessibility. The first four have been considered in several household trip generation studies. Transportation generally refers to long distance travel as intercity travel [1].

* Lecturer, Civil Engineering Department, Military Technical College, Cairo, Egypt.

** Lecturer, Public Works Department, Faculty of Engineering, Ain Shams University, Cairo, Egypt.

*** Lecturer, Civil Engineering Department, Faculty of Engineering, Helwan University, Cairo, Egypt.

**** Professor, Civil Engineering Department, Ryerson University, Toronto, On, Canada. 
The American travel survey (ATS) is a sample of eighty thousands households [2]. Each Household was interviewed four times during the year to determine the number and nature of long distance trips taken by individuals in household. Data of ATS were used to develop the trip generation model presented in this study.

Regression models and cross-classification models are used for estimating the number of trips generated in any studied areas. Regression models have been formulated as simple and multivariate linear and non-linear forms and use a variety of socio-economic and demographic characteristics to determine the tendency to travel. Recently, researchers have focused on developing Poisson regression models to provide more realistic estimates of trips [3]. Cross-classification models were explored in the late 1960s by the Federal Highway Administration [4]. As regression analysis, cross-classification models relate characteristics of households to demand for travel. However, no functional form of this relationship is deduced. Cross-classification models have been more widely used for long-range residential trip generation analysis to overcome some of the inherent problems with regression analysis and it was used in this study.

\section{AMERICAN TRAVEL SURVEY}

\section{Area Classification}

For the presentation of data The ATS divided the states into four census regions, Northeast, Midwest, South and West. Each of the four regions is divided into two or more census divisions. Census divisions are groupings of states that are subdivisions of the four census regions. There are nine divisions for the presentation of data; new England division, middle Atlantic division, east north central division, west north central division, south Atlantic division, east south central division, west south central division, mountain division, and Pacific division.

\section{Metropolitan Areas}

A metropolitan area (MA) is an area of a large population nucleus, together with adjacent communities that have a high degree of economic and social integration with that nucleus. Some MA are defined around tow or more nuclei. To meet the needs of various users, the standards provide for a flexible structure of metropolitan area classify an MA either as a metropolitan statistical area (MSA) or as a consolidated metropolitan statistical area (CMSA), if it has more than one million persons, that is divided into primary metropolitan statistical areas (PMSA). Metropolitan areas shown for the ATS are those areas with estimated 1995 populations of 250,000. The title of an MSA contains the name of its largest central city and up to two additional city names, provided that the additional places meet specified levels of population, employment, and commuting. Generally, a city with a population of 25,000 or more is in the title, regardless of other criteria. The titles of all MSA also contain the name of each state in which the area is located. Each metropolitan area is assigned a four digit code, in alphabetical order nation-wide. In the ATS, non-metropolitan area means any metropolitan area with less than 250,000 in population plus non-urban areas. 


\section{Data Files}

For the public use, the data of ATS are provided in two files; a household trip file (hhtrip.dat) and a person trip file (pertrip.dat). Each record in both files represents a household or person trip, respectively, and its associated geographic, socio-economic, and transportation-related characteristics. Trip variables on both the household trip and person trip files include purpose of trip, mode of transportation, trip distance, number of household members on the trip, and a wide variety of related statistics. All of the data are presented in a manner that guarantees the confidentiality of the respondents. The household trip file contains one record for each trip taken by a household during the sample year. The household trip data includes information about the traveling households size, household and family income, household type, and number of vehicles. A record in the person trip files provides characteristics of each individual person in the household who took a trip. Information on person trips includes such variables as the traveler's race, origin, age, income category, and activity. So if three people in a household of five people take one trip, there is one record in the household file and three records in the person trip file. Information related to these files is presented in several formats to facilitate easy access and use of the data. Also, ATS developed a demographic file, which contains demographic information about the trip maker and the household, such as age, race, sex, income, primary economic activity, and household size and composition. The demographic and household trip files were used in this study of trip generation.

\section{Household Types}

There are two main household types, family households which include categories 01-12 and non-family households that include categories 13-16. Family households are divided into three groups; married couples, female householders, and male householders. Then each group id divided into four categories based on existence and age of children. Nonfamily households are divided into male/female householders living/not living alone.

\section{Household Income}

Household income reported in the ATS is categorical data. Income was presented in 12 categories of them category 01 indicates income less than $\$ 10,000$ and category 12 indicates income of $\$ 150,000$ or more.

\section{Reason for Trip}

The literature on intercity travel demand forecasting models generally distinguishes between business and non-business trip purposes. The ATS actually described twelve purposes for taking a long distance trip. A trip in the ATS is considered to be for business reasons if the reason cited was business, combined business/pleasure, convention, conference, or seminar. Trips made for all other purposes reported in the ATS are assumed non-business trips. The modeled developed in this study concerned 
with the non-business trip purposes assuming that the decision to travel for business purposes is different from the decision to travel for other purposes.

\section{MODEL DEVELOPMENT}

This model aims to estimate the number of trips generated from metropolitan areas using information on income and number of households. Median income was used in this model because of the categorical nature of the reported income data. This may impact the future utility of the model when median income may be determined from another source. The twelve income categories reported in ATS are reduced to three categories in this model. The low income category contains all households with income less than $\$ 25,000$; it includes categories 01-03 introduced in ATS. The median income category, $\$ 25,000$ - $\$ 40,000$, includes categories 04-05 introduced in ATC. The high income category, more than $\$ 40,000$, includes categories 06-12 in ATS.

There are three main steps to develop this model, first step is to determine the percent of households that fall into each income category for each MSA. This can be done using the median income as an input to Figure (1). Second step is to determine percent of households by household type by income category utilizing Figure (2). In this figure, the sixteen household types presented in the ATS were reduced to five categories: 1) married-couple family households with children include household type categories 01-03 in ATS, 2) married-couple family households without children includes household type category 04,3 ) single parent household with children includes categories 05-07 and 0911,4 ) family or non-family households without children includes categories $08,12,13$, and 15, and 5) non-family households not living alone include categories 14 and 16 . The third step is to determine the average trips per household by household type and income category, Figure (3) can be used for this purpose. Finally, the total number of trips generated by each income category can be calculated as;

$$
\begin{gathered}
P_{g h}=H H \times I_{g}(\%) \times A_{g h}(\%) \times\left(P_{H}\right)_{g h}, \text { and } \\
P_{t}=\sum_{g} \sum_{h} P_{g h}
\end{gathered}
$$

Where:

$\mathrm{P}_{\mathrm{gh}} \quad$ number of trips generated in the metropolitan area by householders with income level $\mathrm{g}$ with and household type $\mathrm{h}$ (married with kids, married without kids, etc.).

$\mathrm{HH}$ number of households in the metropolitan area.

$\mathrm{I}_{\mathrm{g}} \quad$ percentage of households in the metropolitan area with income level $\mathrm{g}$ (low, medium, or high).

$A_{g h} \quad$ percentage of households in income level g and household type $h$

$\left(\mathrm{P}_{\mathrm{H}}\right)_{\mathrm{gh}}$ average number of trips generated by householders with income level $\mathrm{g}$ and household type $h$.

$\mathrm{P}_{\mathrm{t}} \quad$ total number of trips generated in the metropolitan area. 
Model development follows that described for the urban trip cross-classification model in Garber and Hoel [5] and that introduced by O'Neill [6]. Applying the metropolitan model to each metropolitan area in a state and summing the results of each application, statewide totals for long distance non-business trips may be obtained.

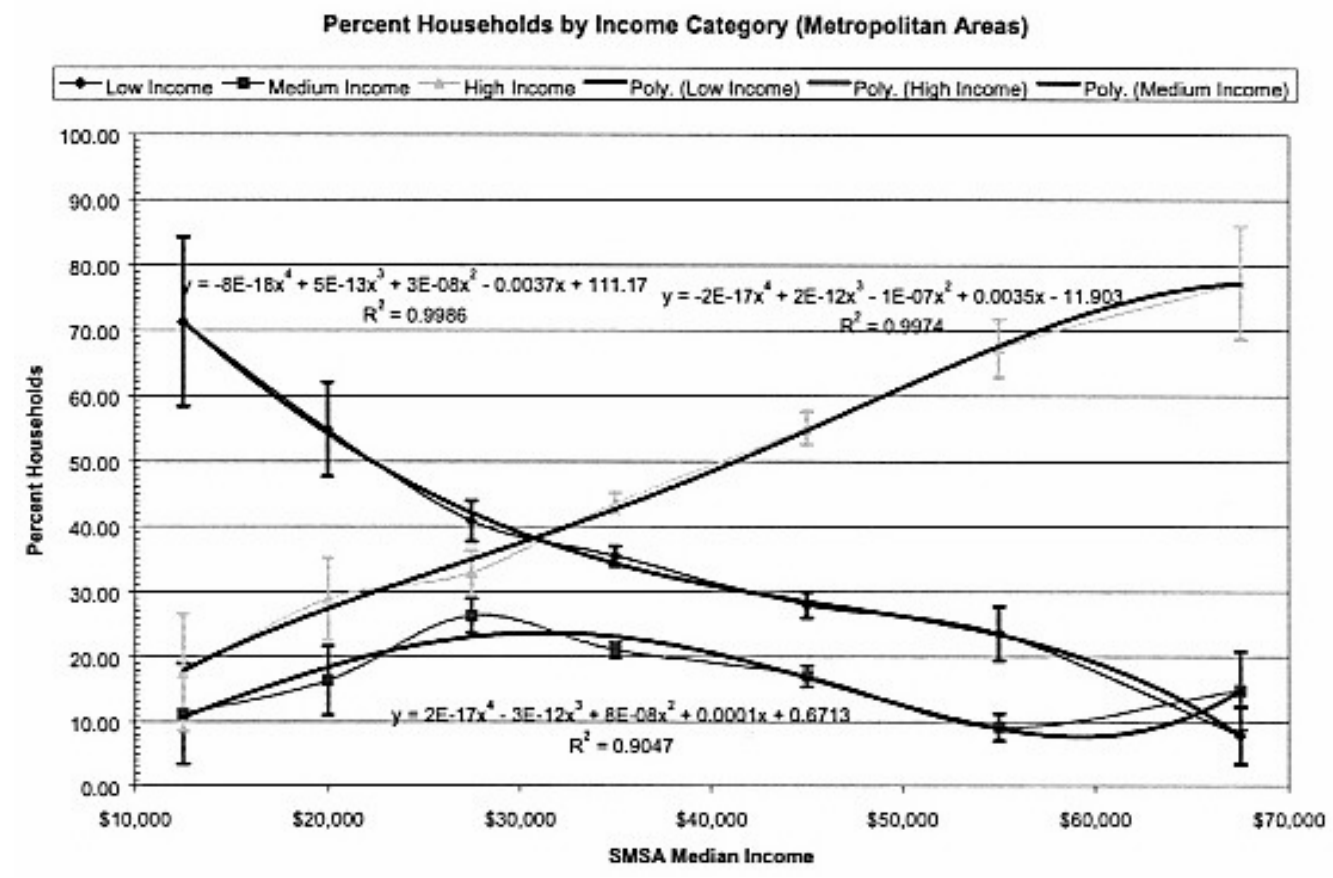

Figure (1) Percent of households by income category [7].

Percent HH by HH Type

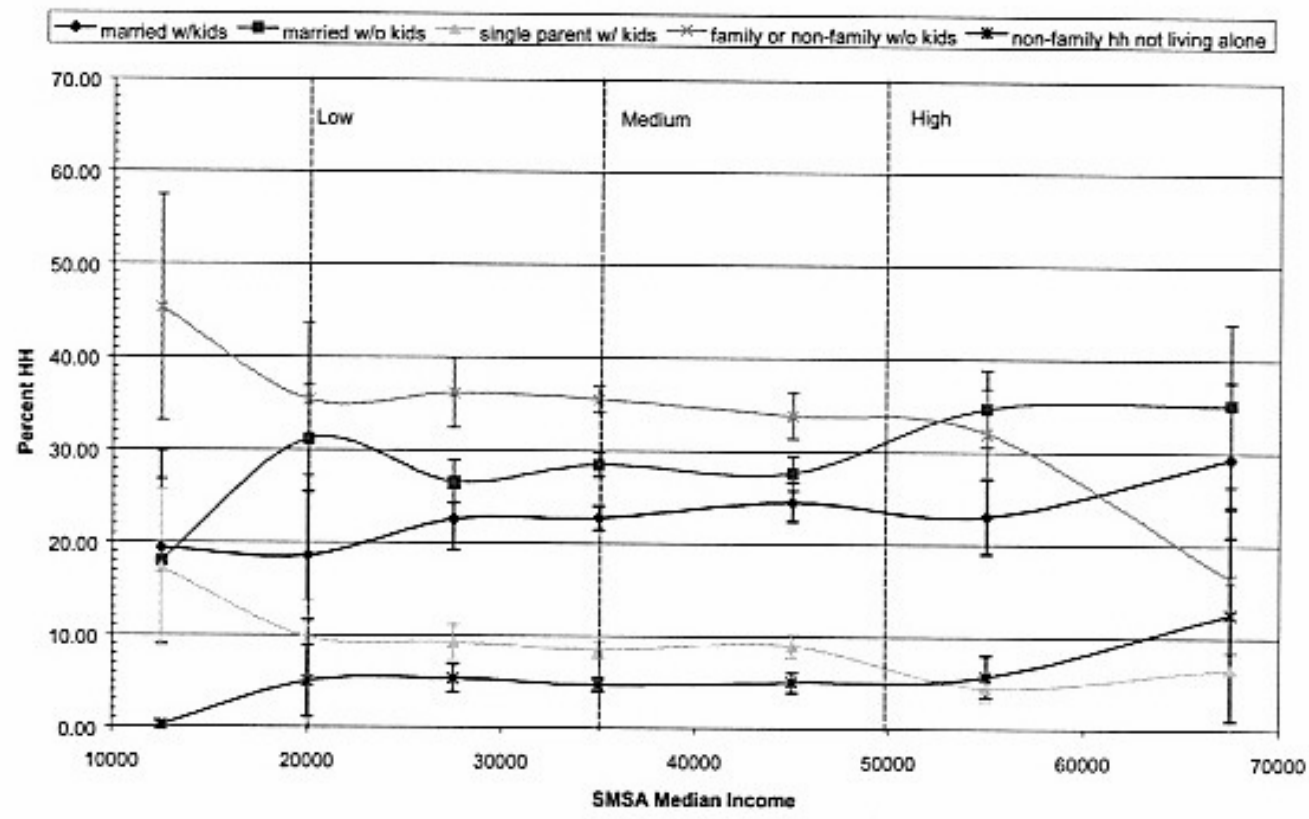

Figure (2) Percent of households by household type [7]. 


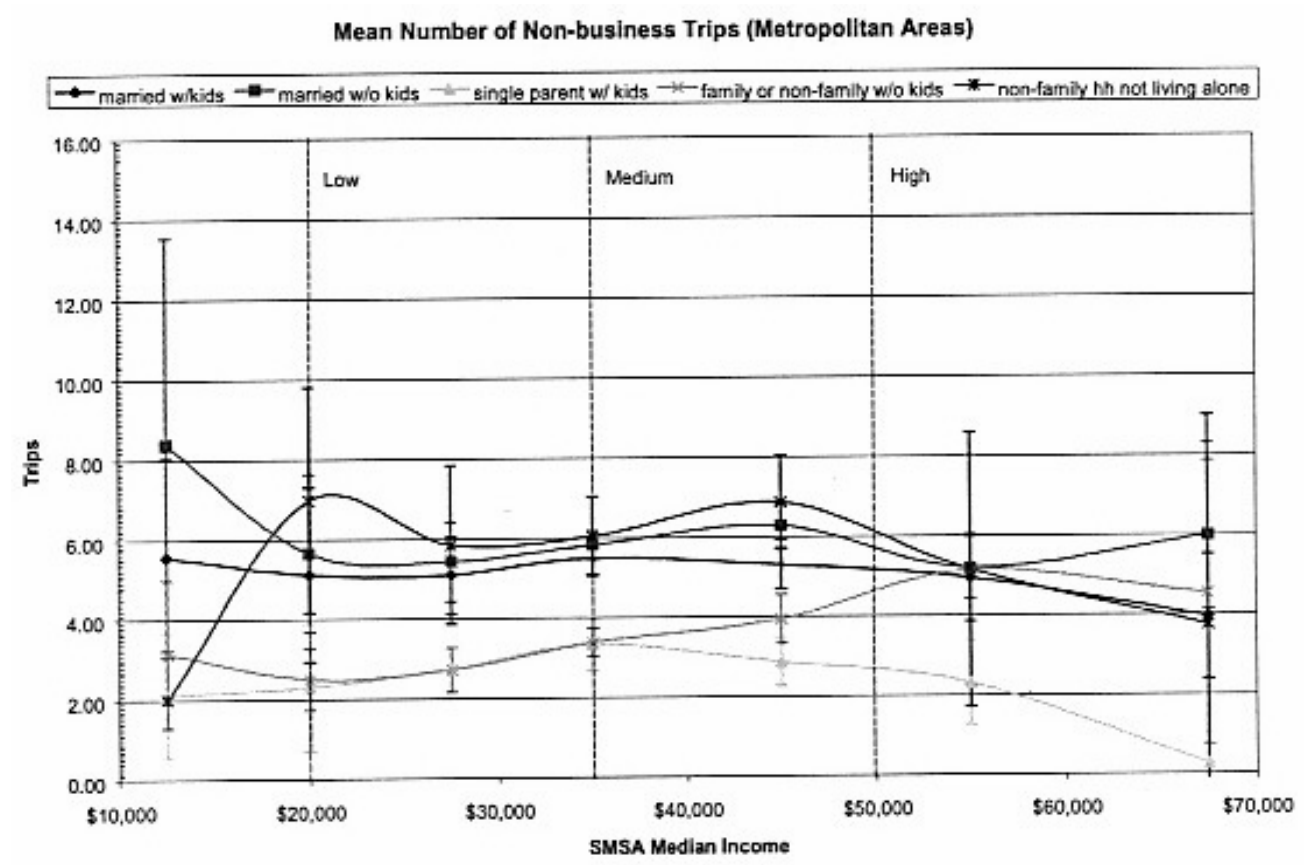

Figure (3) Average number of non-business trips by household type [7].

\section{RESULTS}

The trip generation model developed above can be used to estimate the number of long distance, non-business trips in metropolitan areas. Four metropolitan areas have been chosen, one from each census region, to estimate the total number of non-business trips using ATS. These four metropolitan areas are Oklahoma City, San Diego, Kansas City and Hartford. For each metropolitan area, number of households was found from ATS [8]. Also, the median income was calculated based on the 1995 income [9]. To use Figures (2-3), specific values for low, medium, and high incomes were required. These specific values were estimated for each metropolitan as the mode of income for each income category. In Oklahoma City, $\$ 15,000, \$ 32,500$ and $\$ 50,000$ were used to represent low, medium and high income categories respectively. These values were estimated to be \$15,000, \$32,500 and 70,000 in San Diego. However, in Kansas City $\$ 20,000, \$ 35,000$ and \$65,000 were used to represent low, medium and high income categories respectively. Finally, these values were estimated to be $\$ 20,000, \$ 35,000$ and 70,000 in Hartford.

To investigate the effect of metropolitan income on the total number of non-business trips generated in the metropolitan areas, the median incomes were incorporated based on 1993 and 1997 censuses for each studied metropolitan area. Table (1) presents location and number of households of the studied metropolitans., Tables (2-7) present the calculations and results for Oklahoma city. The effect of increasing income on the total number of trips is shown in Figures (4). 
Table (1) Census data for the studied metropolitan areas.

\begin{tabular}{ccccc}
\hline City & Census Region & Census Division & State & No. of HH \\
\hline Oklahoma & South & West South Central & Oklahoma & 377,905 \\
San Diego & West & Pacific & California & 939,717 \\
Kansas & Midwest & West North Central & Missouri & 705,277 \\
Hartford & Northeast & New England & Connecticut & 463,847 \\
\hline
\end{tabular}

Table (2) Percent of household in each income category, Oklahoma City, OK MSA.

\begin{tabular}{ccccc}
\hline Year & Median Income & Low & Medium & High \\
\hline 1993 & $\$ 30,006$ & 38.5 & 24 & 37.5 \\
1995 & $\$ 31,221$ & 37 & 24.5 & 38.5 \\
1997 & $\$ 34,513$ & 34 & 23 & 43 \\
\hline
\end{tabular}

Table (3) Distribution of household types for the different income categories, Oklahoma City, OK MSA.

\begin{tabular}{lccccc}
\hline Income Level & \multicolumn{5}{c}{ Household Type } \\
\cline { 2 - 6 } & 1 & 2 & 3 & 4 & 5 \\
\hline Low & 19 & 23 & 14 & 42 & 2 \\
Medium & 23 & 27.5 & 8.5 & 35.5 & 5.5 \\
High & 23.5 & 31.5 & 6 & 34 & 5 \\
\hline
\end{tabular}

Table (4) Trips per household for each household type for the different income categories, Oklahoma City, OK MSA.

\begin{tabular}{lccccc}
\hline Income Level & \multicolumn{5}{c}{ Household Type } \\
\cline { 2 - 6 } & 1 & 2 & 3 & 4 & 5 \\
\hline Low & 5.4 & 7.3 & 2.2 & 2.9 & 4 \\
Medium & 5.4 & 5.7 & 3.2 & 3.2 & 5.9 \\
High & 5.1 & 5.7 & 2.7 & 4.6 & 6 \\
\hline
\end{tabular}

Table (5) Total number of trips generated by Oklahoma City, OK MSA, 1993.

\begin{tabular}{cccccc}
\hline $\mathrm{P}_{\mathrm{L}, 1}$ & $\mathrm{P}_{\mathrm{L}, 2}$ & $\mathrm{P}_{\mathrm{L}, 3}$ & $\mathrm{P}_{\mathrm{L}, 4}$ & $\mathrm{P}_{\mathrm{L}, 5}$ & $\mathrm{P}_{\mathrm{L}}$ \\
\hline 149276 & 244283 & 44812 & 177211 & 11639 & 627222 \\
$\mathrm{P}_{\mathrm{M}, 1}$ & $\mathrm{P}_{\mathrm{M}, 2}$ & $\mathrm{P}_{\mathrm{M}, 3}$ & $\mathrm{P}_{\mathrm{M}, 4}$ & $\mathrm{P}_{\mathrm{M}, 5}$ & $\mathrm{P}_{\mathrm{M}}$ \\
112646 & 142168 & 24670 & 103032 & 29431 & 411947 \\
$\mathrm{P}_{\mathrm{H}, 1}$ & $\mathrm{P}_{\mathrm{H}, 2}$ & $\mathrm{P}_{\mathrm{H}, 3}$ & $\mathrm{P}_{\mathrm{H}, 4}$ & $\mathrm{P}_{\mathrm{H}, 5}$ & $\mathrm{P}_{\mathrm{H}}$ \\
169845 & 254448 & 22958 & 221641 & 42514 & 711406 \\
& & & & $\mathrm{P}_{\mathrm{T}}=$ & 1750575 \\
\hline
\end{tabular}


Table (6) Total number of trips generated by Oklahoma City, OK MSA, 1995.

\begin{tabular}{cccccc}
\hline $\mathrm{P}_{\mathrm{L}, 1}$ & $\mathrm{P}_{\mathrm{L}, 2}$ & $\mathrm{P}_{\mathrm{L}, 3}$ & $\mathrm{P}_{\mathrm{L}, 4}$ & $\mathrm{P}_{\mathrm{L}, 5}$ & $\mathrm{P}_{\mathrm{L}}$ \\
\hline 143460 & 234766 & 43066 & 170307 & 11186 & 602785 \\
$\mathrm{P}_{\mathrm{M}, 1}$ & $\mathrm{P}_{\mathrm{M}, 2}$ & $\mathrm{P}_{\mathrm{M}, 3}$ & $\mathrm{P}_{\mathrm{M}, 4}$ & $\mathrm{P}_{\mathrm{M}, 5}$ & $\mathrm{P}_{\mathrm{M}}$ \\
114993 & 145130 & 25184 & 105179 & 30044 & 420529 \\
$\mathrm{P}_{\mathrm{H}, 1}$ & $\mathrm{P}_{\mathrm{H}, 2}$ & $\mathrm{P}_{\mathrm{H}, 3}$ & $\mathrm{P}_{\mathrm{H}, 4}$ & $\mathrm{P}_{\mathrm{H}, 5}$ & $\mathrm{P}_{\mathrm{H}}$ \\
174374 & 261233 & 23570 & 227552 & 43648 & 730377 \\
& & & & $\mathrm{P}_{\mathrm{T}}=$ & 1753690 \\
\hline
\end{tabular}

Table (7) Total number of trips generated by Oklahoma City, OK MSA, 1997.

\begin{tabular}{cccccc}
\hline $\mathrm{P}_{\mathrm{L}, 1}$ & $\mathrm{P}_{\mathrm{L}, 2}$ & $\mathrm{P}_{\mathrm{L}, 3}$ & $\mathrm{P}_{\mathrm{L}, 4}$ & $\mathrm{P}_{\mathrm{L}, 5}$ & $\mathrm{P}_{\mathrm{L}}$ \\
\hline 131828 & 215731 & 39574 & 156498 & 10279 & 553910 \\
$\mathrm{P}_{\mathrm{M}, 1}$ & $\mathrm{P}_{\mathrm{M}, 2}$ & $\mathrm{P}_{\mathrm{M}, 3}$ & $\mathrm{P}_{\mathrm{M}, 4}$ & $\mathrm{P}_{\mathrm{M}, 5}$ & $\mathrm{P}_{\mathrm{M}}$ \\
107952 & 136244 & 23642 & 98739 & 28205 & 394782 \\
$\mathrm{P}_{\mathrm{H}, 1}$ & $\mathrm{P}_{\mathrm{H}, 2}$ & $\mathrm{P}_{\mathrm{H}, 3}$ & $\mathrm{P}_{\mathrm{H}, 4}$ & $\mathrm{P}_{\mathrm{H}, 5}$ & $\mathrm{P}_{\mathrm{H}}$ \\
194755 & 291767 & 26325 & 254149 & 48750 & 815746 \\
& & & & $\mathrm{P}_{\mathrm{T}}=$ & 1764438 \\
\hline
\end{tabular}

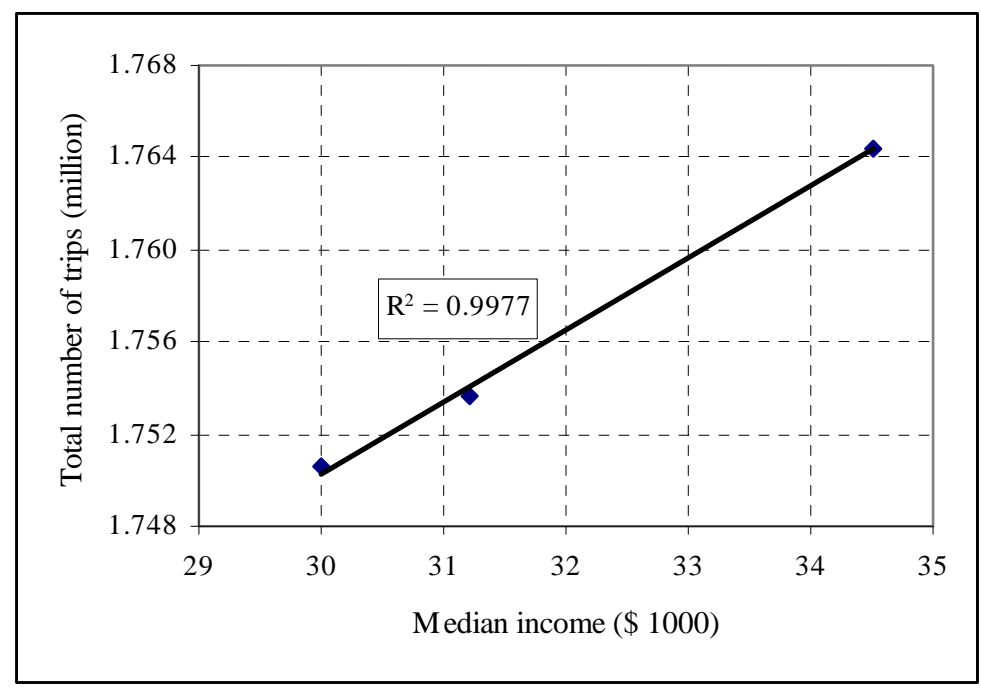

Figure (4) Effect of income level on the total trips, Oklahoma City, OK MSA.

Similar to Oklahoma city, total number of non-business trips was estimated for other three cities located at different census regions. These cities are San Diego, Kansa, and Hartford. Table (8) presents the results for each median income (1993, 1995 or 1997's income). The percentage increases in total trips as the result of the income increase are shown in this table. It is clear that, the relation between income and total trips can be estimated by a linear function with $\mathrm{R}^{2}$ of $0.998,0.99,0.91,0.94$ for the four studied areas respectively, which may be a very good fitting. Generally, total trips slightly increased as the median income increased. If the data over a long-term period are available, the 
developed model and relationship between the number of trips and the median income can be used to estimate accurately the future trips for any metropolitan area. The model and relationships can be calibrated and used for any other area outside the states.

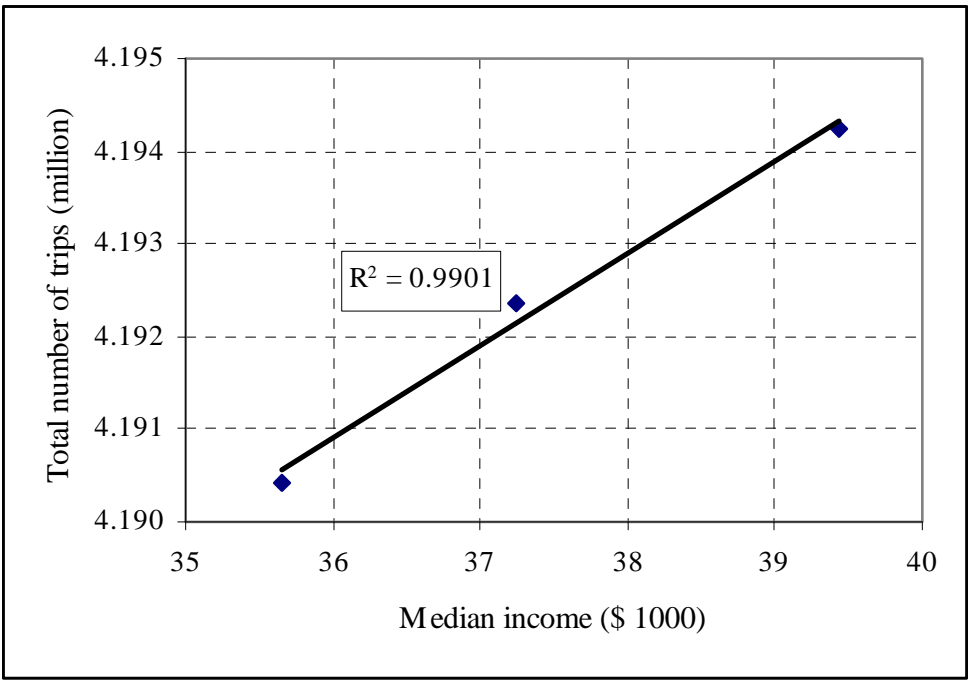

Figure (5) Effect of income level on the total trips, San Diego, CA MSA.

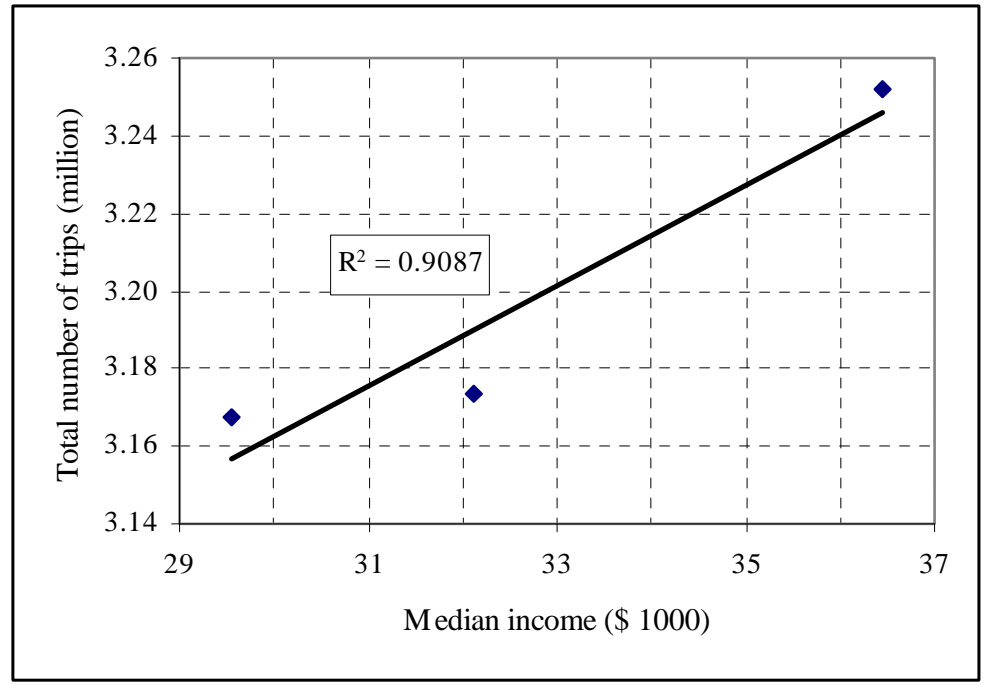

Figure (6) Effect of income level on the total trips, Kansas City, MO-KS MSA.

\section{CONCLUSIONS}

This paper demonstrates how a cross-classification model for long distance non-business trip generation may be developed using data from the 1995ATS. This model may be used by states and metropolitan areas to estimate the number of long distance trips that will be generated during a year. This is a very simple cross-classification model based on 


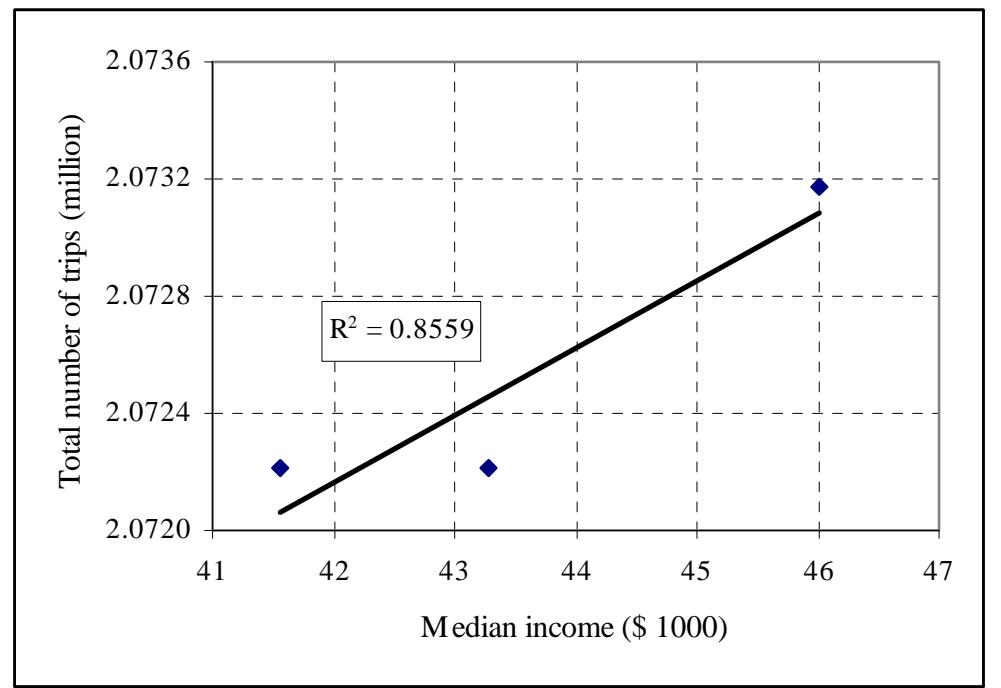

Figure (7) Effect of income level on the total trips, Hartford, CT MSA.

Table (8) Total trips versus median income for different metropolitan areas.

\begin{tabular}{rlccc}
\hline Year & $\begin{array}{l}\text { Median } \\
\text { income }\end{array}$ & $\begin{array}{c}\text { \%-age } \\
\text { increase }\end{array}$ & $\begin{array}{c}\text { Total } \\
\text { Trips }\end{array}$ & $\begin{array}{c}\text { \%-age } \\
\text { increase }\end{array}$ \\
\hline \multicolumn{5}{c}{ Oklahoma City, OK MSA } \\
1993 & 30,006 & --- & $1,750,575$ & --- \\
1995 & 31,221 & 4.05 & $1,753,690$ & 0.18 \\
1997 & 34,513 & 15.02 & $1,764,438$ & 0.79 \\
1993 & 35,648 & --- & $4,190,424$ & --- \\
1995 & 37,239 & 4.46 & $4,192,359$ & 0.05 \\
1997 & 39,427 & 10.6 & $4,194,237$ & 0.09 \\
1993 & Kan Diego, CA MSA \\
1995 & 32,544 & --- & $3,167,237$ & --- \\
1997 & 36,448 & 23.37 & $3,252,020$ & 2.71 \\
1993 & 41,566 & --- & $2,072,213$ & --- \\
1995 & 43,279 & 4.12 & $2,072,216$ & 0.0001 \\
1997 & 46,011 & 10.69 & $2,073,176$ & 0.05 \\
\hline \multicolumn{5}{c}{ Hartford, CT MSA City, MO-KS MSA } \\
\hline
\end{tabular}

two variables. Future work investigates the use of other information to determine the propensity for non-business travel. Particularly stratification of households by age of the householders will be investigated. Transferability of trip generation models has been a problem in urban modeling. This research effort investigated the development of 
individual trip generation models for different geographic regions as well as for different population sizes. The results of these efforts will be reported in forthcoming papers.

- This paper showed how to estimate long distance non-business trips using data from a travel survey.

- The model can be calibrated and used for any area outside the States.

- Generally, total trips slightly increased as the median income increased.

- The relation between income and trips can be estimated by a linear function.

- Having the data over a long-term period, the model can be used to predict the future long distance trips accurately.

\section{FUTURE WORK}

- Due to the lack of data, car ownership was not included in this study. So, extensive future work should be conducted to investigate if car ownership and income level are representative for each other or not.

- It is also recommended to study the effect of income on total number of trips over a long-term period and use of other information, especially stratification of households by age, to determine the propensity for non-business long distance travel.

\section{REFERENCES}

1- O’Neill, Wende, Philip Fulton and Eugene Brown, 'Evaluating the Role of Distance and Location in Statewide Travel Demand Forecasting Using the American Travel Survey" forthcoming publication in the Transportation Research Record, 1999.

2- http://www.bts.gov/ats

3- Wallace, Brett, Fred Mannering, and G. Scott Rutherford, Evaluating the Effects of TDM Strategies on Trip Generation by Using Poisson and Negative Binomial Regression'; Transportation Research Board 78th Annual Meeting Preprint CD-ROM, 1999.

4- FHWA Trip Generation Analysis \#050-001-00101-2, 1975 FHWA Guidelines for Trip Generation Analysis, June 1967.

5- Garber, Nicolas J., and Lester A. Hoel, Traffic and Highway Engineering, West Publishing Co., New York, NY, 1988.

6- http:/www.fhwa.dot.gov//////ohim/travelconf/oneill2.pdf.

7- http:/www.fhwa.dot.gov//////ohim/travelconf/oneill1.pdf.

8- American Housing Survey, Report, U.S. Department of Transportation, Bureau of Transportation Statistics, Washington, D.C., 1995.

9- http://www.census.gov/hhes/www/sapipe/stcty/estimate.html 